\title{
El perenne saqueo patriarcal de la Naturaleza en Nuestramérica: de reflexiones y teorizaciones sin olvidar las luces ecofeministas
}

\author{
Rebeca Arguedas-Ramírez \\ Sistema Nacional de Radio y Televisión \\ de Costa Rica, SINART \\ Académica ICAT-UNA \\ Recibido: 27/10/2015 Aceptado: 18/11/2015 / http://dx.doi.org/10.15359/tdna.32-59.9
}

\section{Resumen}

Se hace un recorrido por algunos conceptos de diversa autoría que han analizado y desarrollado conocimiento alrededor del tema de la colonización de la Naturaleza y los nuevos saqueos, como una constante desde la invasión europea en el siglo XV hasta nuestros días. Asimismo, se incluye una mención acerca de la caracterización del ecofeminismo en América Latina, perspectivas y rutas teóricas sentipensantes de intuiciones esperanzadoras y críticas punzantes muchas veces invisibilizadas.

Palabras clave: globalización, resistencias, América Latina, extractivismo, ecofeminismo, colonialismo interno

\section{Abstract}

This article covers the ideas of several authors who have analyzed and generated knowledge on the subject of the colonization and new plunder of Nature proposed as a constant from the times of the European invasion in the fifteenth century to present day. It further mentions the characterization of eco-feminism in Latin America, and the Sentipensante (sensing/thinking) perspectives and theoretical paths of inspirational intuition towards a sharp criticisms that are often voiceless.

Keywords: Globalization, resistance, Latin America, extractivism, ecofeminism, internal colonialism.

\section{Resumo}

Este artigo entra as idéias de vários autores que analisaram e produziram conhecimento sobre o tema da colonização e nova pilhagem da natureza en Nossa America, proposto por

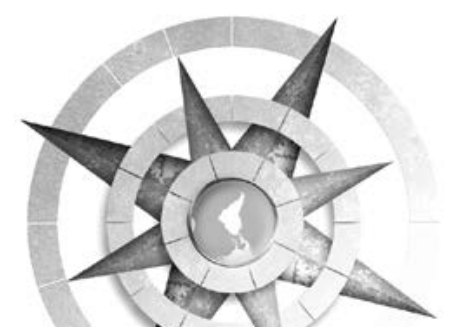
eles como uma constante desde os tempos da invasão europeia no século XV até os dias atuais. Uma caracterização do eco-feminismo na América Latina, e de as perspectivas e caminhos teóricos 
sentipensantes e proposta juntamente com duras críticas que muitas vezes não têm voz.

Palavras chave: Globalização, resistência, América Latina, extrativismo, ecofeminismo, colonialismo interno.

¿Qué es Naturaleza? ¿Es el verdor de la montaña, el agua del río, la inmensidad del mar? ¿Es la biodiversidad ecosistémica planetaria y sus vínculos? ¿A qué le llamamos Naturaleza o medio ambiente?, ¿es lo mismo? ¿Se nos olvida a los seres humanos que como parte de la fauna que somos, aparecemos en este universo como un elemento más de la Naturaleza? ¿Pensamos en nuestras relaciones y dinámicas cotidianas, sociales, políticas y económicas cuando pensamos en Naturaleza? Este puede ser un punto de partida para recorrer el concepto de saqueo de la Naturaleza en América Latina y el mundo.

El cúmulo de elementos biológicos, una sumatoria es la primera aproximación que hace Bohórquez (2013) para definir Naturaleza, pero no se queda allí, continúa, más allá de esa sumatoria y posibles interacciones entre sí, incluye el vínculo de las personas con ella, el imaginario que tenga la humanidad de Naturaleza dentro y no fuera de su definición: «las narrativas, las visiones, los simbolismos y las cosmovisiones a través de las cuales se hace lectura, explicación, comprensión y praxis de lo que identificamos como "la cosa natural».

Somos parte de la Naturaleza, pero más allá de nuestra presencia, la Naturaleza es nuestra conceptualización. En el vínculo con ella, saquear la Naturaleza implica saqueo de nuestras creencias, saqueo de determinadas relaciones que tengan individuos y colectivos con el medio ambiente.

Para Bohórquez desde la época de la conquista española hasta nuestros días la situación no ha cambiado: "el dispositivo de poder colonial hegemónico ha actuado de la misma manera. Impone su dominio para usufructuar los bienes territoriales, ambientales y ecológicos de las comunidades sometidas". (2013: 224) Magnus Möerner (1971) citado por Bohórquez que el

dispositivo colonial que se sustentó en gran parte en el extractivismo, generó lo que denomina la "pigmentocracia", es decir, tal y como denominó Alejandro Lipschutz, la estratificación de la colonización española basada en color de la piel, cuanto más oscura, menos humano se era, o "se es" aún en nuestros días. Y esa diferencia permitió una política de
130 Perenne saqueo patriarcal de la Naturaleza en Nuestramérica: De reflexiones y teorizaciones sin olvidar las luces ecofeministas Rebeca Arguedas-Ramírez

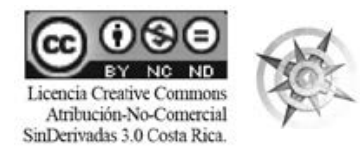


usurpación que los derechos de la población autóctona tenían sobre la geografía, sobre la tierra, sobre los recursos-bienes naturales que por hábitat le correspondían. (Citado por Bohórquez, 232).

\section{Un saqueo de la naturaleza basado} en el racismo instaurado a partir de 1492. Aníbal Quijano se ha referido al patrón colonial del poder como una marca característica de la estructuración del Estado-nación y la dominación en nuestra región desde la conquista hasta nuestros días (Quijano, 2000). De esta manera, la colonialidad del poder hace referencia a un diagrama de dominación basado en la clasificación y jerarquización de la población a partir de la construcción y el uso del concepto de "raza" así como al impacto que esta forma de dominación tiene, entre otras dimensiones, en el terreno del control y la producción de la subjetividad, en especial bajo la forma del "eurocentrismo".

Así se concibe la colonización como estructura, dispositivo instalado y activo hasta hoy en América Latina, base de funcionamiento del extractivismo como herencia de la colonia. Ahora bien, en medio de la globalización, ¿cómo se vive y se concibe el colonialismo? ¿Podemos hablar de nuevos saqueos? Según
Santiago Castro-Gómez (1998), en la perspectiva teórica de autores como Edward Said, Homi Bhabha y Gayatri Spivak:

el colonialismo no es algo que afecta únicamente a ciertos países, grupos sociales o individuos del "Tercer Mundo", sino una experiencia global compartida, que concierne tanto a los antiguos colonizadores como a los antiguos (o nuevos) colonizados. El colonialismo territorial y nacionalista de la modernidad ha desembocado en un colonialismo posmoderno, global y desterritorializado. (p. 227)

Asimismo, Pablo González Casanova utiliza el concepto de colonialismo interno para dar cuenta del proceso de dominación y explotación específico vigente en el nivel nacional en América Latina, más allá de que en el marco internacional estas formas coloniales parecieran haber sido o hubiesen sido superadas, (citado por Seoane y Taddei, 2010). González vuelve a revisar el concepto en el 2006 y amplía, para "colonialización internacional y colonización interior tienden a realizar expropiaciones y despojos de territorios y propiedades agrarias existentes, y contribuyen a la proletarización o empobrecimiento, por depredación, desempleo y bajos salarios, de la

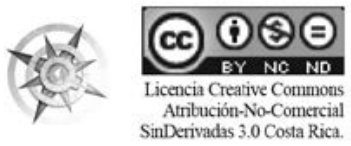

Perenne saqueo patriarcal de la Naturaleza en Nuestramérica: De 131 reflexiones y teorizaciones sin olvidar las luces ecofeministas 
población y los trabajadores de las zonas subyugadas". (p. 423)

Imposible no citar a Eduardo Galeano y Las venas abiertas de América Latina, Francisco Pinto (2013), en una entrevista que le hizo, recuerda cómo el autor describió en su libro con "amplio detalle la descarnada crónica de despojo y humillación a la que ha sido sometida Latinoamérica desde el desembarco de Colón". (s/p) Y hace el recuento, "plata, oro, salitre, azúcar, caucho y un largo etcétera de recursos naturales arrasados en diversos puntos del continente a fin de enriquecer las ambiciosas arcas de los imperios del norte, dejando como herencia la miseria una vez agotada la veta y la tierra" (s/p).Talvez ese recuento debió haber empezado por el cacao, semilla sagrada especialmente para la cultura maya. Este sirve acá como emblema de la implicación del saqueo, un elemento que no está solo, es él y la multiplicidad de relaciones concretas y simbólicas de los otros elementos con él, incluyendo las personas y sus creencias.

El despojo, por tanto, resulta uno de los mecanismo, medulares del colonialismo en el siglo XXI; el extractivismo, entonces, una de las formas que toma el despojo en la globalización. Gudynas, al ser entrevistado por Nuria del Viso de FUHEM Ecosocial
(2012), definió extractivismo diciendo que "en un sentido acotado responde en cierta medida a una herencia histórica (...) el extractivismo como una extracción de grandes volúmenes de recursos naturales con altos impactos sociales y ambientales y que están esencialmente orientados a los mercados globales".

Gudynas (2009) aclara que extraer per se no está mal, es decir, como uno de los vínculos que son parte de la naturaleza también está esa convivencia que implica que pájaros, insectos, humanos, hongos nos alimentemos, construyamos nidos, vivamos. Por tanto,

no todas las extracciones de recursos naturales son una forma de "extractivismo", sino que abordamos un conjunto específico, tanto por su volumen como por su orientación exportadora. Bajo esta idea son extractivistas no solo muchas explotaciones mineras y petroleras, sino también otras actividades de alto impacto y globalizadas, como los monocultivos de soja o la cría de camarones, e incluso bajo ciertas condiciones lo puede ser el turismo. $(\mathrm{s} / \mathrm{p})$

Considera así que el extractivismo es un componente más de la globalización contemporánea.
132 Perenne saqueo patriarcal de la Naturaleza en Nuestramérica: De reflexiones y teorizaciones sin olvidar las luces ecofeministas Rebeca Arguedas-Ramírez 
Gudynas (2009) enfatiza en dicha entrevista que

es un estilo evidentemente insustentable" y afirma que "si se sigue este camino nos encontraremos que algunos recursos se agotarán, quedarán los efectos ambientales a lo largo de varias generaciones y los pretendidos beneficios económicos se disiparán rápidamente. Por lo tanto, cualquier discusión sobre modelos al desarrollo debe debatir simultáneamente las alternativas al extractivismo. $(\mathrm{s} / \mathrm{p})$

\section{La paradoja del progresismo en} Nuestramérica en medio de la globalización. Lo que Galeano apuntaba como la extracción de recursos naturales para beneficio solo de los países ricos del primer mundo en la actualidad son gobiernos considerados progresistas en la región, estos que continúan explotando los recursos naturales, en lo que se llama el neoextractivismo. El extractivismo, según Gudynas (2009), es una de las banderas de los gobiernos progresistas en América Latina. De acuerdo con él, a pesar de los profundos cambios políticos continentales hacia la izquierda, los sectores extractivistas mantienen su importancia y son uno de los pilares de las estrategias de desarrollo actuales.
Patriarcalismo y saqueo. Este dispositivo de poder colonial hegemónico de saqueo perenne, instaurado desde 1492, actuó y actúa desde el patriarcado, pero, iquién apunta o destaca la relevancia desde este punto? ¿Es relevante o clave en la búsqueda de respuestas y soluciones que permitan salir de un círculo vicioso de dependencias centro-periferia? Sigo la revisión de los mismos autores y poco se vincula al respecto.

La permanencia y la intensificación del extractivismo responde a la concepción y práctica del crecimiento, para Carlos Taibo (2013) uno de los grandes mitos de la economía oficial es el del crecimiento. Para él "la economía oficial dice que el crecimiento genera cohesión social, que facilita el asentamiento de los servicios públicos y que dificulta el crecimiento del desempleo y de la desigualdad. Pero lo cuestiona:

El crecimiento económico no provoca necesariamente cohesión social, y se traduce a menudo en agresiones medioambientales literalmente irreversibles, facilita el agotamiento de recursos escasos que no van a estar a disposición de las generaciones venideras y nos sitúa en un marco de un modo de vida esclavo que nos aconseja concluir que seremos más felices cuantos más bienes acertemos a 
consumir. Todas estas "verdades" merecen ser cuestionadas hipercríticamente. (p. 133)

Siguiendo su sugerencia, ¿a cuál necesidad de "crecimiento" cimentado en el saqueo responden las prácticas que han permitido la permanencia y la intensificación del extractivismo? ¿Es la lógica patriarcal del poder el motor del saqueo, de la acumulación por desposesión, del extractivismo, del "crecimiento" insostenible desde la colonia como período y hasta los días de globalización del siglo XXI?

Para Seoane y Taddei (2010) "la acumulación por desposesión de los bienes comunes de la naturaleza" (123), concepto desarrollado por Harvey (2004), es uno de los signos distintivos de la globalización neoliberal en nuestra región. Esta es la dinámica que asume en la actualidad la continuación de una extendida y violenta experiencia de saqueo y explotación de Nuestramérica, que desde el siglo XV estuvo estrechamente asociada al nacimiento y la expansión del capitalismo mundial.

"La mundialización liberal no sólo ha implicado una creciente polarización económica y social y de poder a nivel global. No sólo ha supuesto una reactualización del imperialismo en un sentido de recolonización de la periferia”, (p. 138) dice Seoane en su intervención realizada en el I ${ }^{o}$ Encuentro contra el saqueo y la contaminación de los bienes comunes, por el poder popular y el cambio social, y continúa diciendo:

Ello ha venido acompañado o ha promovido una nueva división internacional de trabajo como países proveedores de materias primas ("commodities") y ha implantado en nuestros países una lógica particular de acumulación del capital que llamamos de acumulación por desposesión. ¿Y qué significa esta acumulación por desposesión? Llamamos así al proceso por el cual un conjunto de bienes que eran comunes se transforman -son convertidos- en mercancías; es decir, son apropiados privadamente para su venta-intercambio y/o para su uso en el proceso de producción capitalista.

Refiere con ello a un proceso amplio y diverso que mercantiliza la vida en general, dice "por ejemplo, a través del patentamiento de la biodiversidad y su uso comercial, ¿no?". Biopiratería será entonces otra forma sistemática de extractivismo, ícono del neocolonialismo, protagonizada por parte de la gran industria transnacional farmaceútica-agroindustrial.

Silvia Ribeiro y Silvia Rodríguez (2015), ambas ecofeministas, han

134 Perenne saqueo patriarcal de la Naturaleza en Nuestramérica: De reflexiones y teorizaciones sin olvidar las luces ecofeministas Rebeca Arguedas-Ramírez
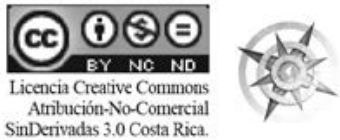
profundizado sobre el tema. Rodríguez, activista y teórica-académica de la UNA de Costa Rica, concluye en su artículo para Grain poco más de dos décadas de la entrada en vigencia del acta de la UPOV-91, de los ADPIC, del CBD y del nacimiento de la Revista Biodiversidad, sustento y culturas, estamos ante una renovada expansión de los derechos de propiedad intelectual $(\mathrm{s} / \mathrm{p})$. Continúa:

Frente a ellos, no podemos cerrar los ojos sino por el contrario continuar en la lucha junto con los pueblos y movimientos sociales, recogiendo sus percepciones de la realidad, compartiendo nuestros hallazgos, analizando con ellos y ellas los cantos de sirenas que nos presentan las corporaciones y gobiernos que las acuerpan, y planeando nuevas respuestas. Al hacerlo, es importante no partir de cero sino recabar experiencias y revisar las posibilidades y limitaciones de experiencias y propuestas hechas por ejemplo en Costa Rica (2003-2008), en México (2012-2013), en Colombia (2012), en Chile (2014) y en Argentina (2013-2014) en contra de las leyes de semillas y de UPOV.

Al respecto de esta "renovada expansión de los derechos de propiedad intelectual" que apunta Rodríguez, resulta indispensable llegar al pensamiento de Vandana Shiva, que ha sido referente y dialogante para América Latina en cuanto a la biopiratería. Shiva, con su obra Biopiratería, El saqueo de la naturaleza y del conocimiento (2001), plantea cómo las grandes corporaciones del norte hegemónico se han abocado a patentar los recursos genéticos del sur. Allí destacan nombres como Monsanto y grandes transnacionales farmaceúticas en busca de genes de organismos vivos, desde los microorganismos del suelo hasta los de animales y seres humanos, en particular de los pueblos indígenas, que desean la monopolización y privatización de la vida, manipulando exitosamente para incluir los derechos de propiedad intelectual en el marco del GATT. Así, el norte se aseguró la adopción de un conjunto uniforme de leyes de propiedad intelectual para facilitar ese propósito.

Ribeiro, Shiva y otros autores cuestionan la palabra bioprospección por su condición de legalidad, ya que el nuevo régimen de registro de patentes abre las puertas para la transnacionales. Por tanto, acuña como nombre más justo biopiratería, dado que aduce que la apropiación de los recursos biológicos que han sido desarrollados a través de generaciones por los pueblos del sur es un acto de piratería.

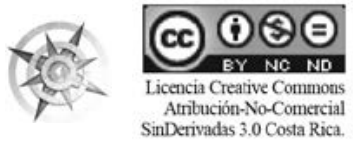

Perenne saqueo patriarcal de la Naturaleza en Nuestramérica: De 135 reflexiones y teorizaciones sin olvidar las luces ecofeministas 
Shiva (2001) señala que:

se reconocen derechos de propiedad intelectual únicamente cuando el conocimiento y la innovación producen ganancias, no cuando responden al bien común. La creatividad sólo se pone al servicio de la obtención de beneficios y la acumulación de capital; el bien social ya no se reconoce. (p. 146)

\section{Para Maristella Svampa (2013):}

el neoextractivismo desarrollista contempla actividades consideradas tradicionalmente tales (...) y aquellas ligadas al nuevo sistema agroalimentario, como los agronegocios o la producción de biocombustibles. Incluye también aquellos proyectos de infraestructura previstos por la Iniciativa para la Integración de la Infraestructura Regional Suramericana (IIRSA), programa consensuado por varios gobiernos latinoamericanos en el año 2000 en materia de transporte (hidrovías, puertos, corredores bioceánicos, entre otros), energía (grandes represas hidroeléctricas) y comunicaciones, cuyo objetivo estratégico es facilitar la extracción y exportación de las materias primas hacia sus puertos de destino. (p. 34)
Svampa advierte que:

la escala de los emprendimientos nos advierte también sobre la gran envergadura de las inversiones (se trata de actividades capital-intensivas y no trabajo-intensivas), así como sobre el carácter de los actores involucrados y la concentración económica (grandes corporaciones transnacionales) (...)Así, la megaminería a cielo abierto, la expansión de la frontera petrolera y energética (que incluye también la explotación de gas no convencional o shale gas, con la tan cuestionada metodología del fracking), la construcción de grandes represas hidroeléctricas, la expansión de la frontera pesquera y forestal, en fin, la generalización del modelo de agronegocios (soja y biocombustibles), constituyen las figuras emblemáticas del neoextractivismo desarrollista. (p. 35-36)

Al respecto, Consenso de los Commodities" señala que:

conlleva una carga no solo económica sino también político-ideológica, pues alude a la idea de que existiría un acuerdo -tácito, aunque, con el paso de los años, cada vez más explícito- acerca del carácter irrevocable o irresistible de la actual dinámica extractivista (...) ha ido cimentando las bases de una ilusión desarrollista que

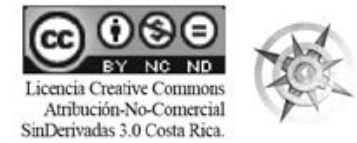


recorre, más allá de las diferencias y los matices, el conjunto de los países latinoamericanos. (p. 35)

\section{Respuestas al saqueo. Para Saeone (2006):}

(...) las experiencias forjadas a nivel local o nacional por los propios movimientos sociales han tendido a construir rápidamente vínculos más allá del espacio nacional, constituyéndose en muchos casos en parte importante de las campañas contra el libre comercio y la militarización y jugando un papel en lo que ha dado en llamarse "movimiento altermundialista. (p. 102)

La defensa del carácter de bienes comunes de los recursos naturales se ha expresado en la confrontación social contra las devastadoras consecuencias medioambientales, la destrucción del hábitat y el desplazamiento forzoso de poblaciones. Así también ha tomado cuerpo en los cuestionamientos de los efectos y el modelo de apropiación privada de estos recursos y de los beneficios derivados de su explotación. (Seoane, 2006, p. 85).

Cabe mencionar que el concepto de bienes comunes lo desarrolló la autora Elinor Ostrom (2001) como respuesta a una teoría económica que ha clasificado los bienes de forma binaria en públicos y privados.

\section{Para Leff (2005):}

en el surgimiento de los movimientos de defensa de los bienes comunes naturales aparece la noción del territorio como "lugar donde la sustentabilidad se enraíza en bases ecológicas", y se postulan formulaciones alternativas de la relación entre la humanidad y la naturaleza y de la organización societal (citado por Saeone y Taddei, 2010).

Para Gudynas (2011):

las transiciones hacia alternativas al desarrollo otorgan un papel destacado a los objetivos ambientales. Están alineadas con al reconocimiento de los derechos de la Naturaleza, tal como ha sucedido en la reciente Constitución de Ecuador; lo que implica una fuerte estrategia en conservación que impida nuevas extinciones de especies y asegure la viabilidad de los grandes tipos de ecosistemas. (p. 72)

Gudynas amplía una crítica medular frente a la lógica del saqueo, y es la del concepto de desarrollo y progreso "estas transiciones implican una serie de rupturas con las ideas clásicas del desarrollo (...) La clásica idea del progreso, de origen occidental, queda en entredicho, y se exploran alternativas bajo otras concepciones del bienestar y la buena vida (p. 198 )”. 
Y destaca algunas medidas: reducir sustancialmente el consumo de materia y energía, es decir, desmaterialización de los procesos productivos; desacoplar las metas de estas alternativas del crecimiento económico únicamente; ajustar los procesos productivos a las capacidades de los ecosistemas (brindar recursos y recibir impactos), asegurando así la supervivencia de la biodiversidad y orientar los procesos productivos para la erradicación de la pobreza, así como combate de la opulencia.

¿Está hablando Gudynas de un proceso que implica despatriarcar el pensamiento al romper con una lógica de poder de violencia y despojo?

Seoane (2006) dice: "Este es un campo amplio donde existe un impresionante número de iniciativas y líneas de reflexiones" y menciona el "Buen Vivir" "en que se basan en las ontologías de diferentes pueblos indígenas".

Y continúa: "A esto se deben sumar los primeros ensayos gubernamentales en el diseño de planes para trascender el desarrollismo convencional" (p. 86). Dice Seaone, que no olvida la base conceptual del gobierno de Correa, hoy cuestionado por movimientos indígenas y campesinos en plena agitación violenta en todo el país, justamente por rasgos recrudecidos del modelo extractivista:

el mejor ejemplo tiene lugar en Ecuador, donde la Secretaría Nacional de Planificación ha elaborado un Plan Nacional del Buen Vivir (SENPLADES, 2009) y, más allá de su real aplicabilidad actual, es importante advertir que uno de sus ejes conceptuales es salir de una economía post extractivista para pasar a otra basada en el conocimiento y los servicios $(\mathrm{s} / \mathrm{p})$.

A pesar de las profundas contradicciones lo cierto es que "el buen vivir" está presente en las nuevas constituciones andinas:

Las ideas del Buen Vivir lograron formalizarse en las nuevas constituciones de Bolivia (aprobada en 2009) y Ecuador (2008) (...) En el caso ecuatoriano, se expresa bajo la idea del sumak kawsay en kichwa, que ha sido defendido e invocado a lo largo de los últimos años, hasta cristalizar políticamente en el proceso constituyente de 2007 y 2008. 10 (...) Con el Buen Vivir se ha renovado la crítica al desarrollo, pero se ha ido mucho más allá, ya que se quiere superar la idea convencional del progreso (en su deriva productivista) y del desarrollo (en tanto dirección única y lineal). (Gudynas y Acosta, 2011, p. 73)

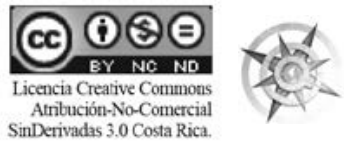


Maristella Svampa (2011) señala cómo:

el actual escenario ilustra no solo de un continuado acoplamiento entre extractivismo neodesarrollista y neoliberalismo, expresado de manera paradigmática por los casos de Perú, Colombia o México, sino también entre extractivismo neodesarrollista y gobiernos "progresistas", en un contexto de fortalecimiento de las capacidades estatales, lo cual complejiza aún más la problemática ligada a la multiescalaridad de los conflictos y las alternativas existentes, en donde se entrecruzan políticas públicas, diferentes lógicas de acción y territorialidades diversas $(\mathrm{s} / \mathrm{p})$.

Se impone la dinámica de la globalización, ¿será que también se sigue imponiendo y proponiendo desde una lógica patriarcalista?

En el 2010, en ocasión del Seminario Derechos de la Naturaleza y Sumak Kawsay: una visión desde los pueblos del sur, que se celebra en la Facultad Latinoamericana de Ciencias Sociales (FLACSO), Vandana Shiva, galardonada en 1993 con el Premio Nobel Alternativo, ofreció una conferencia magistral sobre Democracia de la Tierra y Derechos de la Naturaleza. Subrayó el avance de Ecuador por haber incorporado en su Constitución el reconocimiento de la Naturaleza como sujeto de derechos, así como el planteamiento de una filosofía de desarrollo holística del país a través del Sumak Kawsay o Buen Vivir. En su opinión, este avance normativo es una plataforma para el respeto y reconocimiento de la diversidad en todas sus formas. Y manifestó que la semilla es el primer eslabón de la cadena alimentaria, salvarla es nuestro deber, compartirla es nuestra cultura.

¿Y el patriarcado? ¿Y el ecofeminismo? Allí Shiva también destacó los tres principios del ecofeminismo: la tierra está viva, es sagrada y es la conexión entre todos los seres vivos; la Naturaleza fue reemplazada por el patriarcado, y las mujeres, parte de la Naturaleza, se encuentran subordinadas frente al hombre y tanto a la producción como al respeto a todo ser viviente. Ecofeminismo y buen vivir se toman de las manos.

Varias de las autoras mencionadas han hecho sus aportes alimentadas en la praxis y en la teoría desde el ecofeminismo en América Latina. ¿Y a qué nos referimos si hablamos de ecofeminismo? Según Celina A. Lértora Mendoza, el ecofeminismo latinoamericano,

surgió hace unos veinte años de la confluencia de dos corrientes independientes, la deep ecology y el 
feminismo, se vincula en América Latina sobre todo a corrientes anteriores y ya arraigadas: la filosofía y la teología de la liberación. Ello se debe fundamentalmente a que el feminismo latinoamericano, a su vez, se ha vinculado estrechamente a estas corrientes y sus temas se han conjugado alrededor de cuestiones relativas a la praxis concreta de liberación. $(\mathrm{s} / \mathrm{p} ; \mathrm{s} / \mathrm{f})$ (En: www.cecies.org/asrtuculo.asp?id=387)

Resume los puntos teóricos y programáticos básicos del ecofeminismo del norte, que a su vez toma los siguientes tópicos de las corrientes originarias: de la ecología profunda, la propuesta de proteger a la $\mathrm{Na}$ turaleza, buscando una alternativa cultural al modo de vida actual y reemplazándola por una cultura provida, del feminismo, toma sus dos afirmaciones fundamentales:

1. que el "género" (entendido como rol que corresponde a cada sexo en una determinada comunidad) es un constructo social y no se deriva necesariamente del sexo biológico;

2. que en esta diferenciación de roles (sesgo de género) la primacía ha correspondido al varón, que ha dominado a la mujer (patriarcado) y ha establecido los modos masculinos de comportamiento y/o pensamiento como modelos para toda la humanidad (androcentrismo).

El ecofeminismo toma también del feminismo el método hermenéutico de la deconstrucción y lo aplica al nuevo objeto: la relación hombre-naturaleza; así asume más acentuadamente la vinculación con los movimientos de liberación y de derechos humanos.

Como posición central, el ecofeminismo sostiene que la dominación de la naturaleza y de la mujer son paralelas y que no se revertirán aisladamente. Dos de las teólogas feministas más destacadas de América Latina -Elsa Támez e Ivone Gebara- nombran el ecofeminismo como la tercera fase de la teología feminista en América Latina. Támez dice de esta fase:

el desafío es muy radical pues implica reinventar toda la teología cristiana. Hay incomodidad en releer los grandes temas teológicos como la cristología, la trinidad y la eclesiología por su androcentrismo. Se reconoce que las implicaciones de la reconstrucción van más allá de la ortodoxia. (2010: 113)

Sin lugar a dudas, Ivone Gebara, teóloga feminista brasileña, es la

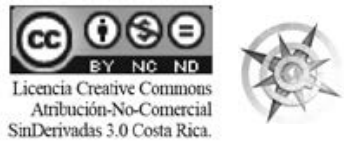


más conocida ecofeminista en América Latina. Ha inspirado cientos de mujeres con su visión de un "ecofeminismo holístico", según Mary Judith Ress. (2010)

\section{Lértora considera que}

aunque todavía con escaso desarrollo teórico, el ecofeminismo latinoamericano se perfila como una corriente en crecimiento, que se interesa por los graves problemas ambientales presentes en la región, sobre todo en relación con el mayor perjuicio relativo que causan a los pobres y marginados, cuyo hábitat está siendo devastado por prácticas depredadoras y correlativas ideologías perniciosas. ( $\mathrm{s} / \mathrm{p})$

Para Lértora el desarrollo del ecofeminismo latinoamericano, es aún incipiente, pero sí tiene perfil propio y destaca dos rasgos identificatorios: la revaloración de las cosmovisiones autóctonas (antiguas) y el énfasis en la praxis de liberación.

Gebara analiza y critica la construcción del ecofeminismo, y su gestión meramente teórica

Para mí la cuestión desafiante no es la pugna entre los diferentes modos de interpretar las vidas de las mujeres y el ecosistema, o el reduccionismo de teorías, sino la destrucción de la vida mientras estamos discutiendo las teorías. No, yo no estoy en contra de las teorías, pero sospecho que algunas discusiones están reforzando más la lógica patriarcal del capitalismo que un estilo de vida alternativo real (...) Me parece que el feminismo no puede dejarse tentar por teorías masculinas y competitivas, que están enamoradas de ellas mismas, sin buscar teorías de una reforma estructural y acciones orientadas a la justicia. (citado por Ress, 2010 p. 120)

El ecofeminismo y el feminismo comunitario y de los pueblos indígenas van de la mano o se mimetizan.

El feminismo comunitario se comprende en un contexto en el que la defensa del territorio es prioritaria, en forma conjunta con la lucha contra la violencia hacia las mujeres y la protección del cuerpo como lugar sacro y de enunciación. De esta manera, es necesario que el cuerpo se convierta en un territorio (territorio-cuerpo: defensa de los derechos sexuales y reproductivos, deconstrucción de los roles de género y las relaciones de poder) de resistencia frente a la expropiación y violencia históricas, así como la tierra debe ser defendida porque es el territorio (territorio-tierra: defensa del territorio, de la naturaleza) en el que conviven los cuerpos. 
Algunas autoras consideran el movimiento Chiptko, inspiración para ecofeminismo en América Latina. Vandana Shiva es una de las personas referentes de este movimiento, el cual fue en un principio de carácter ecologista, aunque con una destacada participación de las mujeres. Se constituyó, en sus orígenes, sobre el principio de la no-violencia activa, en defensa de los recursos forestales y la conservación de la naturaleza para frenar su degradación, y ha ido incorporando una visión más amplia sobre los problemas ambientales. Especial relevancia ha adquirido la lucha contra las biopatentes, al considerar que son la invasión de las formas de vida por parte del capitalismo patriarcal, que hace desaparecer la reproducción y la reemplaza por la producción, para que pueda seguir existiendo un crecimiento del capital.

Para el capitalismo patriarcal, cuestiones como la maternidad, los cuidados o la agricultura de supervivencia, son definidas como no productivas, porque no se compran ni se venden, no se genera capital y no existe el crecimiento económico. Forman parte del ciclo de la reproducción, y se han ido incorporando en el sistema capitalista de manera gradual como producción, a través de elementos como las biopatentes, los fertilizantes e incluso la propia destrucción de la naturaleza. En definitiva, para el capitalismo patriarcal, la reproducción en sí misma, de la vida, no es considerada como un bien si no se puede incorporar al mercado.

Chipko sirve de referencia para mostrar cómo los movimientos por la reclamación de los derechos de las mujeres surgen de las luchas contra la violación de estos, aunque en un principio no sean "de género". De esta manera, se demuestra que los movimientos para la reivindicación de derechos en el nivel público pueden traducirse en una vindicación de los derechos en el nivel personal.

De pensamiento y origen autóctono, mencionar a Julieta Paredes de procedencia aymara, resulta indispensable. Ella es un referente de América Latina para el mundo del feminismo comunitario indígena y tanto su crítica como su propuesta al buen vivir se puede reducir a la máxima feminista que dice "Le féminisme ou la mort" (El feminismo o la muerte), título del libro en el que fue utilizado por primera vez, en 1974, el término ecofeminismo por la francesa Françoise d'Eaubonne. No se puede descolonizar sin despatriarcalizar", en aymara sería que no puede haber pachacuti sin warmicuti, no puede haber un buen vivir sin igualdad entre hombres y mujeres, no se puede

142 Perenne saqueo patriarcal de la Naturaleza en Nuestramérica: De reflexiones y teorizaciones sin olvidar las luces ecofeministas Rebeca Arguedas-Ramírez
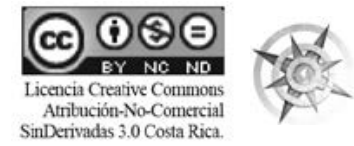
lograr el pachacuti ("cambio de la tierra") que es una nueva era profetizada en la Tradición Andina para iniciarse en "nuestra época", la época de los pueblos indígenas.

Reflexiones finales. En cuanto a la condición de mujer y el extractivismo sin duda es de mayor impacto en la vida de los pueblos indígenas, especialmente en las mujeres y los niños, en lo que se puede denominar "feminización de la pobreza", un rasgo más de la misoginia. Este se traduce en altos índices de femicidios en su esfera más visible de la violencia, es decir, como punta de iceberg, pero, en la violencia explícita menos visible y en la sútil, se fundamenta una de control y acaparación que comparte el origen de esta violencia contra la Naturaleza, constante del saqueo de la Pachamama de Nuestramérica.

Para algunas corrientes ecofeministas, romper con los dualismos será el camino hacia una sociedad igualitaria y hacia la sustentabilidad (Warren, 1996). Resulta, si no definitivo, sustancial incorporar la revisión de desarrollo y género, cuestionarlos de manera profunda, si se pretende dar respuesta certera a la necesidad de poner un alto al saqueo de la Naturaleza.
La revisión de documentos, de conocimiento desarrollado acerca la condición colonial de América Latina, pone en evidencia que sí hay un trabajo acucioso para cuestionar "desarrollo", "progreso", "crecimiento", pero no se incorpora no se considera, no se integra el tema de género y poco se asimila de las intuiciones ecofeministas, al menos no explícitamente.

Vemos gobiernos progresistas, mayoritarimente de líderes masculinos, y resulta inevitable para mí decir que el machismo cruza sus decisiones y los vuelve a la derecha capitalista, mientras mujeres y niños están en primera fila en defensa de sus territorios (cuerpo-Naturaleza).

Siguen tomándose decisiones por líderes quienes aunque con sensibilidades que han querido posicionarse progresistas, siguen vislumbrándose en fantasías de "ganar la competencia" y derrotar al enemigo, en lugar de crear propuestas autóctonas, las cuales consideren otra lógica que no sea el crecimiento y la acumulación, el proceso que implica alejarse de la visión antropocentrista de la Naturaleza. Lo anterior, claro está, sin pretender ser simplista y obviar las condiciones de dependencia, así como el poderío transnacional sobre la autonomía gubernamental de las naciones. 
Y cierro con las palabras de Mary Judith Ress (2010) en su texto Espiritualidad ecofeminista en América Latina:

Reconstruir el cuerpo de la tierra, el cuerpo humano y nuestra relación con todos los cuerpos vivientes. Esta es la tarea del ecofeminismo. ¿Y el sueño del eco- feminismo? Anhelar el reconocimiento fundamental de que somos un solo Cuerpo Sagrado con todos sus matices y diversidad. Nada menos. (p. 124)

\section{Referencias bibliográficas}

Bohórquez Caldera, L. A. (2013). Colonización de la naturaleza: una aproximación desde el extractivismo en Colombia. Ágora U.S.B. 13 (1) pp 221-239. Recuperado de http:// www.scielo.org.co/scielo.php?pi$\mathrm{d}=$ S1657-80312013000100010\&script=sci_arttext

Del Viso, N. (2012). Cualquier discusión sobre modelos de desarrollo debe debatir simultáneamente las alternativas al extractivismo. Entrevista a Eduardo Gudynas. Recuperado de http://www.rebelion.org/noticia. php?id=151301

Delbene-Lezama, L. (2015). Género, Ecología y Sustentabilidad. Grupo Permanente de Trabajo sobre Alternativas al Desarrollo. Montevido, Uruguay: Fundación Rosa Luxemburg/Abya Yala.
González Casanova, P. (2006). Colonialismo interno. (Una redifinación). Biblioteca Virtual CLACSO. Disponible en: blibliotecavirtual.clacso.org.cr/ ar/libros/campus/merxs/P4C2casanova.pdf

Gudynas, E. (2009). Diez tesis urgentes sobre el nuevo extractivismo. Contexto y demandas bajo el progresismo sudamericano actual. Recuperado de http://www.extractivismo.com/noticias/extractivismoquito09.html. . (2011). Caminos para las transiciones post-extractivistas. En: Alaiza, A y Gudynas, E; eds: Transiciones Postextractivismo y alternativas al extractivismo en Perú. Perú: Red GE y CLAES.

Gudynas, E. y Acosta, A. (2011). La renovación de la crítica al desarrollo y el buen vivir como alternativa. Revista Internacional de Filosofía Iberoamericana y Teoría Social (53), 71-83.

Gudynas, E. (2012). Entrevista, Cualquier discusión sobre modelos de desarrollo debe debatir simultáneamente las alternativas al extractivismo.

Lértora Mendoza, C. (s. f.) Ecofeminismo latinoamericano. Proyecto: Diccionario del pensamiento alternativo II. Fepai. Recuperado de http://www. cecies.org/articulo.asp? $\mathrm{id}=387$

Pinto, F. (2013). Las venas de Amércia Latina aún están abiertas. http://www. ecoportal.net/EcoNoticias/Las_venas_de_America_Latina_aun_estan_abiertas

144 Perenne saqueo patriarcal de la Naturaleza en Nuestramérica: De reflexiones y teorizaciones sin olvidar las luces ecofeministas Rebeca Arguedas-Ramírez 
Seoane, J. (2006). Movimientos sociales y recursos naturales en América Latina: resistencias al neoliberalismo, configuración de alternativas. OSAL, Observatorio Social de América Latina (año VI no. 17 may-ago 2005). CLACSO. Recuperado de http://bibliotecavirtual.clacso.org.ar/clacso/ osal/20110313052811/14cseoane.pd

Seoane, J. y Taddei, E. (2010). Recolonización, bienes comunes de la naturaleza y alternativas de los pueblos. Brasil: Diálogo de los Pueblos y Geal.

Svampa, M. (2013). Consenso de los Commodities y lenguajes de valoración en América Latina. Revista Nueva Sociedad (244).
Ress, M. J. (2010). Espiritualidad ecofeminista en América Latina. Conspirando. Revista latinoamericana de ecofeminismo, espiritualidad y teología. Recuperado de http://www.conspirando.cl/ judyress@yahoo.com

Taibo, C. (2013). Doce preguntas sobre el decrecimiento. En Autonomía $\mathcal{E}$ Autogestión. Disponible en: www.osalde. org

Shiva, V. (2001). El saqueo de la Naturaleza y la biopiratería. Barcelona: Icaria Ed. 